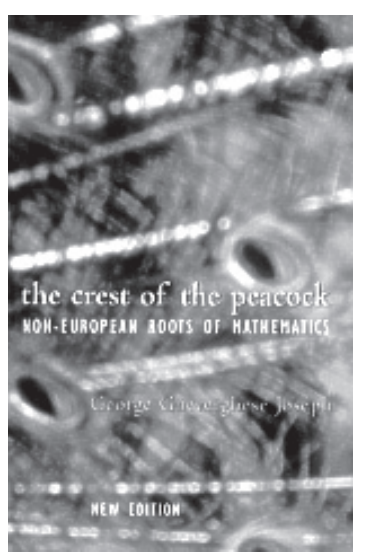

George Gheverghese Joseph

\title{
The Crest of the Peacock: Non-European Roots of Mathematics
}

2nd. ed. London: Penguin Books, 2000

Reviewed by Abdul Karim Bangura

In her article, "Good-Bye Pythagoras?" (in The Chronicle of Higher Education, October 6,2000 , pp.16-17), Elizabeth Greene cites the following cases of academic institutions where ethnomathematics has been thoroughly embraced:

- Eduardo Jesús Arismendi-Pardi teaches the concept of slopes by using the geometric designs in Navajo rugs at Orange Coast College, California.

- Ron Eglash employs African fractals in computer-graphics simulations courses at Rensselaer Polytechnic Institute.

- Arthur B. Powell works out river-crossing problems based on different cultures in an algebra course at the Newark campus of Rutgers University.

- Jim Berta teaches about the Cartesian coordinate system using a cultural analogy of street mapping in towns settled by Mormons at Utah State University.

Greene adds that, in college classes in algebra, calculus, geometry, statistics, and the history of mathematics, among other subjects, and in degree programs for future elementary- and secondary-school teachers, professors are using ethnomathematics to define a new method of teaching mathematics.

All of these professors can now have a valuable text for their courses - i.e. George Gheverghese Joseph's The Crest of the Peacock: Non-European Roots of Mathematics. In this pioneering book, Joseph clearly demonstrates that human beings everywhere have been capable of innovative and advanced mathematical thinking. He traces the history of mathematics from the Ishango Bone in Central Africa and the Inca quipu of South America about 20,000 years ago to the dawn of modern mathematics, when the Arabs changed the contours of algebra around A.D. 830.

What motivated this work is Joseph's desire to correct the widely held belief that mathematics was essentially a European product. This is because, according to him, the standard treatment of the history of non-European mathematics is marked by a deep-rooted 
historiographical bias in the selection and interpretation of facts, and that mathematical activity outside Europe has as a consequence been ignored, devalued or distorted.

In this second edition, Joseph retains the basic format, content and structure of the first one. These are augmented by updates and second thoughts incorporated into notes on each chapter appended at the end in a new section entitled "Reflections."

Joseph's ability to put together such an effulgent work is a reflection of his life story. Born in Karala, southern India, Joseph lived there for nine years. He received his early schooling in Mombasa, Kenya, when his family moved there. He later studied at the University of Leicester, and then worked for six years as an Education Officer in Kenya before returning to the University of Manchester to complete his port-graduate studies. He has held visiting teaching appointments in many parts of the world, including Central and East Africa, Australia, India, New Zealand, Papua New Guinea, and the United States.

The essence of Joseph's masterpiece hinges upon what Stuart Glendinning Hall describes in his thought-provoking essay, "Towards a Working Non-Linear Science of Empowerment" (presented at the Ninth Annual International Conference of the Society for Chaos Theory in Psychology and the Life Sciences in Berkeley, California, July 23$26,1999)$. As Hall puts it, the idea that there could be a "people's knowledge" substantially equivalent to "educated knowledge" is acknowledged by Edwin Lazlo in terms of the "growing convergence between the mystical worldview (predominantly, but by no means exclusively, Eastern) and the emerging paradigm of reality among scientists at the cutting edge of contemporary knowledge." It is rare to find anyone arguing this kind of equivalent in the West because, continues Hall, the colonization of consciousness by the values of need and knowledge has had longer to run: "European mathematics is mathematics; all other mathematics is anthropology. That explains why this other mathematics belongs to what has been called ethnoscience" (a la Thomas Crump in his 1990 work, The Anthropology of Numbers).

What Joseph accomplishes, therefore, is to highlight the myth in the perception that, again following Hall, "people's collective silence is correlated with stupidity, when it is first and foremost an adaptive response to an environment where people perceive they do not have a voice." Thus, Joseph's book is a valuable collection for every scientist, natural, behavioral, or social.

\section{About the reviewer}

Abdul Karim Bangura holds a Ph.D. in Political Science from Howard University, a Ph.D. in Policy Sciences (with a concentration in Development Economics) from the University of Maryland Baltimore Graduate School, a Ph.D. in Linguistics from Georgetown University, and towards the completion of a Ph.D. in Computer Science at Columbus University. He is currently Researcher-In-Residence at the Center for Global Peace, Assistant Professor of International Relations, Coordinator of the Islamic Lecture Series, and Coordinator of the National Conference on Undergraduate Research in the School of International Service at American University; Professorial Lecturer III in Political Science at Howard University; and Director of The African Institution in Washington, DC. From 1993 to 2000, Bangura taught Political Science and International 
Studies, served as Special Assistant to the President and Provost, and founded and directed The Center for Success at Bowie State University. He also has taught at Georgetown University and Sojourner-Douglass College. He is the author of 19 books and more than 200 articles in refereed journals and other sources. His recent books include United States-African Relations: The Reagan-Bush Era (2001); United States Congress and Bilingual Education (2001); Historical Political Economy of Washington, D.C. (2000); and Chaos Theory and African Fractals (2000). His recent, refereed articles and book chapters include "Measurable Effects of Multilingualism in Africa" (International Journal of the Sociology of Language 2000), "Divisive Barbarity or National Civilization: Linguistic Presuppositions of the Sierra Leone National Anthem as a Tool to Teach Peaceful Behavior" (International Journal of Sierra Leone Studies and Reviews 2000), "Ethnicity's Threat to Peace" (in Elias and Turpin), and "Metaphors of Global Ethics: An African Spiritual and Religious Perspective" (in Bushrui et al. 1999). He also is Editor-In-Chief of both the Journal of Research Methodology and African Studies and the African Journal of Languages and Linguistics. Bangura is the Vice President-Elect of the Association of Third World Studies and a member of many other scholarly organizations. He has received many teaching and other scholarly and community service awards, and he is fluent in about a dozen African and six European languages. 